Original Article

\title{
OPTIMIZATION OF DIFFERENT PARAMETERS FOR THE EXTRACTION OF POLYPHENOLS AND PROANTHOCYANIDINS FROM PISTACIA VERA HULLS
}

\author{
ZAM WISSAM \\ Department of Analytical and Food Chemistry, Faculty of Pharmacy, Al-Andalus University for Medical Sciences, Tartous, Syrian Arab Republic \\ Email: ws.sarah2005@gmail.com
}

Received: 01 Sep 2019, Revised and Accepted: 16 Nov 2019

\section{ABSTRACT}

Objective: Pistachio (Pistacia vera L.) hull are usually discarded as waste, which can lead to environmental pollution even a significant portion of polyphenols are often present in high concentrations in the outer parts of fruits. In this way, using a pistachio hull as a source of bioactive compounds will increase the value of pistachio production and offer valorization for a useless by-product.

Methods: Different ethanol concentrations (5, 10, 25, 50, 75 and $95 \%)$ were investigated and the extraction efficiency at extraction temperature from 20 to $90{ }^{\circ} \mathrm{C}$ and extraction times from 5 to 45 min was studied. The extraction yield of total polyphenols and proanthocyanidins from the pistachio hull and the antioxidant activity of the extract were evaluated.

Results: The obtained results indicated relationships between the tested parameters and extraction yield. The maximum yield for total polyphenols and proanthocyanidins was obtained with $25 \%$ ethanol at $60{ }^{\circ} \mathrm{C}$ for $15 \mathrm{~min}(13.91 \pm 0.72$ and $5.86 \pm 0.45 \mathrm{~g} / 100 \mathrm{~g}$ dry weight, respectively). DPPH radical scavenging activities of extracts were proved to have a linear relationship with the polyphenols yield in the extracts $\left(\mathrm{R}^{2}=0.9907\right)$ with a maximum DPPH radical scavenging activity of $60.25 \%$.

Conclusion: These findings propose that pistachio hull extracts can be a valuable source of bioactive compounds.

Keywords: Pistacia vera, Hulls, Polyphenols, Proanthocyanidins, Extraction, Solvent, Temperature, Time, DPPH

(C) 2019 The Authors. Published by Innovare Academic Sciences Pvt Ltd. This is an open-access article under the CC BY license (http://creativecommons.org/licenses/by/4.0/) DOI: http://dx.doi.org/10.22159/ijpps.2019v11i12.35556

\section{INTRODUCTION}

Fruit and vegetable processing residues and wastes are considered as an environmental problem. Phenolic compounds, secondary metabolites and biologically active molecules found in plants, are often present in high concentrations in these processing residues which caught up the interest of researchers [1]. Over the last decade, the interest for these natural components has increased because of their role in nutrition and human health [2-5]. These phenolic compounds can also be used as natural antioxidants and functional food ingredients to replace their synthetic equivalents and for the preservation of food due to their protective impacts against microorganisms [6-8].

Pistachio (Pistacia vera L.), is a plant member of the Anacardiaceae family and native to Asia [9]. Different parts of Pistacia species including leaves, kernels, hulls and gum have caught up the interest of researchers due to their biological activities such as antioxidant potential, antimicrobial and anti-inflammatory activities [10-12]. It has been proved that Pistacia species are rich sources of phenolic compounds including flavonols, flavanones, isoflavons, flavan-3-ols, proanthocyanidins and anthocyanin [13]. Pistachio hull is the largest by-product of pistachio industry, which is accumulated every year at harvest time and can lead to environmental pollution. Considering the high phenolic content of the outer parts of fruits, pistachio hull has caught up the interest of researchers which had proved that pistachio hull extracts have antioxidant, antimicrobial and antimutagenicity activities $[12,14,15]$.

The extraction of compounds from plant materials is the first step in the utilization of phytochemicals in the preparation of dietary supplements or nutraceuticals, food ingredients, pharmaceutical, and cosmetic products [16]. Polyphenols are generally more hydrophilic than lipophilic owing to their phenolic nature. Therefore, free polyphenols along with oligomers such as proanthocyanidins can be readily extracted by solvents such as methanol, ethanol, acetonitrile and acetone, or by their mixtures with water [17].
Extraction time and temperature, as well as the concentration of the extraction solvent, are the crucial parameters affecting the extraction yield. Therefore, the aim of the present study was to evaluate the effect of different parameters on the extraction yield, polyphenol and proanthocyanidins content in pistachio hull extracts and their antioxidant activity.

\section{MATERIALS AND METHODS}

\section{Chemical and reagents}

Folin-Ciocalteu reagent 2N (Sigma-Aldrich, Switzerland), gallic acid (Sigma-Aldrich, China), 2,2-Diphenyl-1-picrylhydrazyl (DPPH) (Sigma-Aldrich, USA). Ethanol and methanol were obtained from Sharlau (Spain). 1-butanol and hydrochloric acid were obtained from Surechem (England)

\section{Equipment}

Micropipette 100-1000 $\mu \mathrm{l}$ (Iso lab, Germany), moisture analyzer balance (Precisa, Switzerland), centrifuge (Shanghai surgical instruments factory, China), spectrophotometer (Jasco V-530, USA).

\section{Sample preparation}

Mature healthy pistachio nuts were harvested from a village nearby Aleppo city, Syria during September 2018. A voucher specimen is deposited in the herbarium (number 1384) of the Laboratory of Pharmacognosy, Al-Andalus University for Medical Sciences, Syria. The hulls of the harvested nuts were removed, dried, ground and the fraction was sieved using a 250-mesh sieve and stored in a freezer at $-20^{\circ} \mathrm{C}$ until being used. The final moisture content of the hull was less than $5 \%$ (w/w \%).

\section{Extraction procedure}

One gram of accurately weighed milled-sieved powder was mixed with $50 \mathrm{ml}$ of ethanol at different concentrations $(5,10,25,50,75$ and $95 \%$ ) and stirred at $400 \mathrm{rpm}$ for different time periods ranging from 5 to $45 \mathrm{~min}$ at a wide range of temperatures from 20 to $90^{\circ} \mathrm{C}$. 
Subsequently, the extracts were filtered through a series of filter papers, followed by collecting filtrates in reagent bottles covered with aluminum foil to avoid light exposure. Extraction by each solvent for different temperatures and time periods was performed in three triplicates. The total polyphenols and proanthocyanidins concentrations, as well as the radical scavenging activity, were measured.

\section{Total polyphenol content}

The total phenolic content was determined using a modified version of the Folin-Ciocalteu colorimetric method [18]. To a mixture of $1 \mathrm{ml}$ extract and $4.5 \mathrm{ml}$ distilled water, $0.5 \mathrm{ml}$ of Folin-Ciocalteu reagent was added. Then, $4 \mathrm{ml}$ of $\mathrm{Na}_{2} \mathrm{CO}_{3}(7.5 \%)$ was added and the mixture was vortexed. The sample was incubated for $30 \mathrm{~min}$ at $40{ }^{\circ} \mathrm{C}$ and absorbance were measured at $734 \mathrm{~nm}$. Gallic acid was used for the calibration curve.

\section{Proanthocyanidins content}

The proanthocyanidin content in the extract was determined by the acid-butanol assay according to the method of Porter et al. [19]. A sample of $200 \mu \mathrm{l}$ extracts diluted with $300 \mu \mathrm{l}$ of acetone $70 \% .3 .0 \mathrm{ml}$ of butanol-HCL reagent and $0.1 \mathrm{ml}$ of $2 \%$ ferric acid were added. The mixture was vortexed and put in the heating block at 97 to 100 ${ }^{\circ} \mathrm{C}$ for $60 \mathrm{~min}$. The tube was then allowed to cool and absorbance was recorded at $550 \mathrm{~nm}$.

\section{DPPH radical-scavenging activity}

DPPH radical-scavenging activity was performed according to the method proposed by Brand-Williams et al., with certain modifications [20]. Aliquots of $200 \mu \mathrm{l}$ of samples were mixed with 2 $\mathrm{ml}$ of $100 \mu \mathrm{M}$ DPPH methanolic solution. The reaction mixture was vortexed and then incubated for $30 \mathrm{~min}$ at room temperature. The absorbance was read at $520 \mathrm{~nm}$ against a blank. The ability to scavenge the DPPH radical was calculated using the following equation [21]:

$$
\text { DPPH scavenging effect }(\%)=\left[\frac{(A 0-A 1)}{A 0} * 100\right]
$$

\section{RESULTS AND DISCUSSION}

\section{Influence of solvents}

Solvents, such as water, ethanol, methanol, propanol, acetone, ethyl acetate, and their mixtures have been used for the extraction of polyphenols, often with different proportions of water [22]. Alcohols are known as the most suitable solvents for polyphenols extraction because of their suitable physical properties. Additionally, polyphenols are polar compounds, which usually are extracted with polar solvents such as ethanol and methanol [23].

The total polyphenols and proanthocyanidins yield in pistachio hull extracts obtained using ethanol at different concentrations show significant differences. As seen in fig. 1, ethanol $25 \%$ show the highest total polyphenols and proanthocyanidins yield $(11.69 \pm 0.67$ and $5.55 \pm 0.37 \mathrm{~g} / 100 \mathrm{~g}$ dry weight). This can be explained by the low solubility of oxygen in $25 \%$ ethanol samples, which play an important role in preventing the degradation reactions of polyphenols [24]. Additionally, the increase in solubility of polyphenols upon the addition of water to-alcoholic solvents could be due to the weakening of the hydrogen bonds between polyphenols and proteins, normally present in plant cells in aqueous solutions [25]. It could also be due to the increase of ionization of the polyphenols in such solutions. Özbek et al. previously proved that the maximum yield of polyphenols from pistachio hull could be obtained using $50 \%$ ethanol ( $32.9 \mathrm{~g}$ dry extract/100 g dry matter) which is in accordance with our results [1].

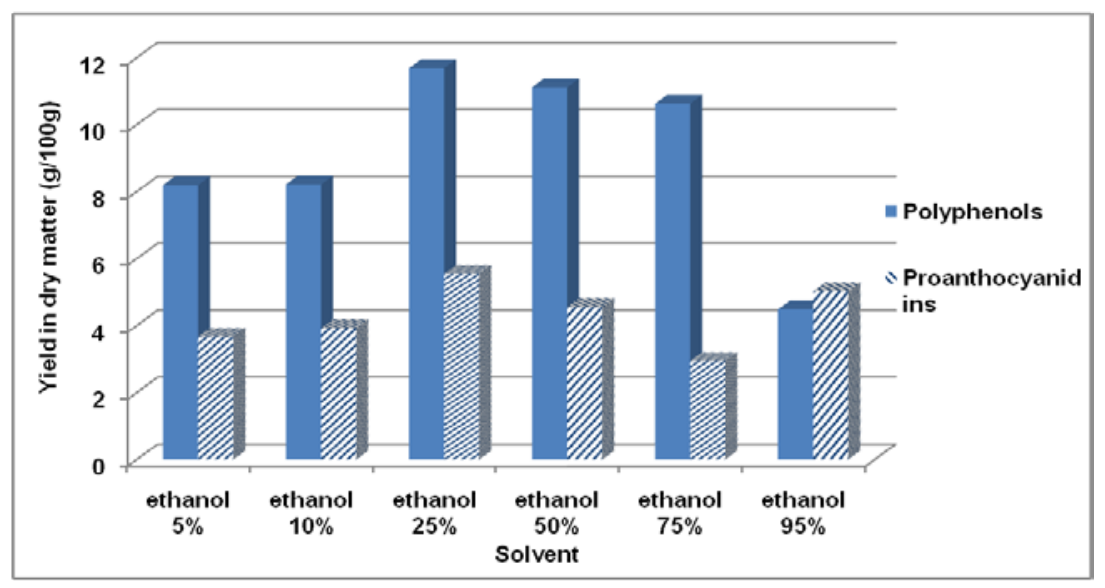

Fig. 1: Effect of different ethanol at different concentrations on total polyphenols and proanthocyanidins yield, As shown in fig. (2) the DPPH radical scavenging activity of extracts has a linear relationship with the polyphenols yield in the extracts $\left(R^{2}=0.9907\right)$

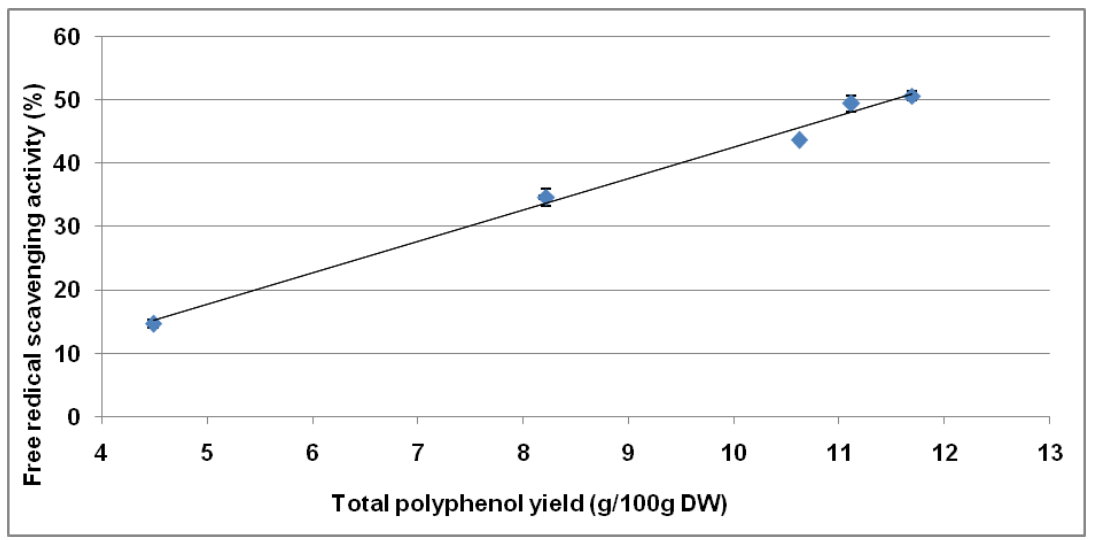

Fig. 2: The relationship between total polyphenols yield and DPPH radical scavenging activity 


\section{Influence of extraction temperature}

Besides the selection of the suitable solvent, extraction temperature is an important factor that affects solute extraction yield. In order to investigate temperature influence on total polyphenols and proanthocyanidins content, $25 \%$ aqueous ethanol was used. Temperatures over the range of 20 to $90{ }^{\circ} \mathrm{C}$ were used. According to the results presented in fig. 3 , the highest extractability was observed at the temperature of $60^{\circ} \mathrm{C}$ and the lowest at the temperature of $20^{\circ} \mathrm{C}$. $\mathrm{S}$. However, no significant difference $(\mathrm{P}<0.05)$ was observed between 60 and $80{ }^{\circ} \mathrm{C}$. Therefore, a fixed maximum temperature of $60^{\circ} \mathrm{C}$ was adopted. Similar results were previously obtained during the extraction of phenolic compounds from grape seeds using 50\% ethanol [26]. Sulaiman et al. proved that optimal temperature for the extraction of phenolic compounds from Clinacanthus nutans Lindau was $60{ }^{\circ} \mathrm{C}$ using water: ethanol solvent ratio of 90:10 v/v\% [27]. Theoretically, an increase in temperature increases the efficiency of the extraction since plant tissues are softened and the weak interactions affect the cell membranes. Additionally, high temperatures decrease the viscosity of the solvent, thus facilitating its passage through the solid substrate mass. As a result, phenolic compounds can be easily extracted into the solvent [28]. However, very high temperatures could cause oxidation and degradation of the desired compounds which would decrease the extraction yield [29].

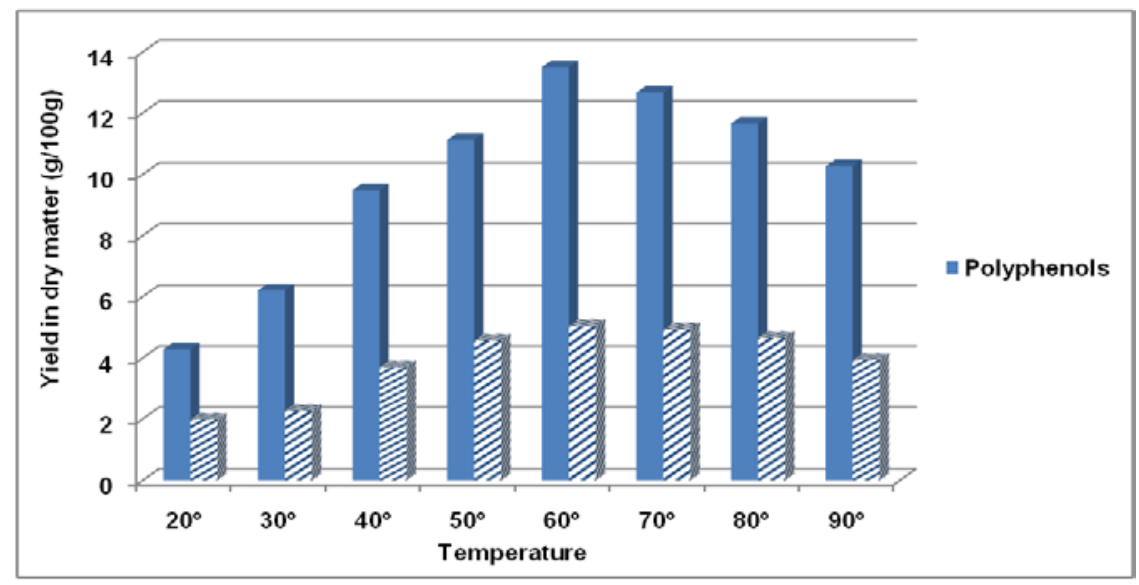

Fig. 3: Effect of extraction temperatures on total polyphenols and proanthocyanidins yield

\section{Influence of extraction time}

Several studies had proved that both high temperature and long exposure time can reduce the extraction yield, because of temperature sensitivity and enzymatic degradation and oxidation of polyphenols, as well as polymerization among insoluble constituents [30]. Additionally, a longer time of extraction can damage extracted natural antioxidants and degrade extract quality [31]. As shown in fig. (4) as extraction time increased (5 to $15 \mathrm{~min}$ ), the yield of polyphenols and proanthocyanidins also increased. Times longer than $30 \mathrm{~min}$ has been shown to cause rapid polyphenols and proanthocyanidins degradation. DPPH activity was evaluated for the optimal extract and was found to be $60.25 \%$.

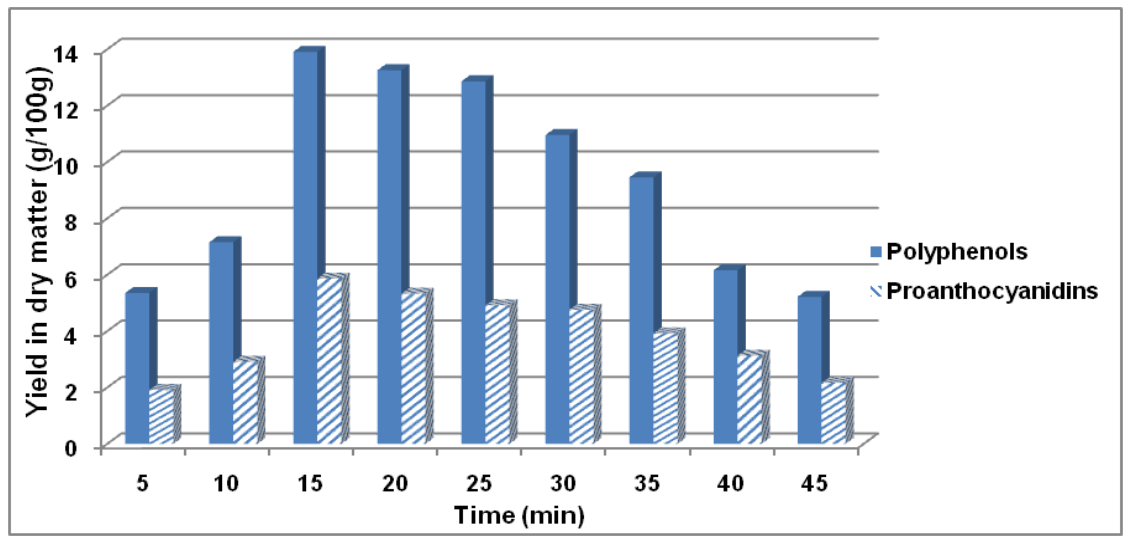

Fig. 4: Effect of extraction time on total polyphenols and proanthocyanidins yield

\section{CONCLUSION}

The yield of chemical extraction depends on the type of solvents with varying polarities, extraction time, temperature, and chemical composition and physical characteristics of the samples, which reflects the conflicting actions of solubilization and analyte degradation by oxidation. Therefore, it is of critical importance to select efficient extraction procedures and to maintain the stability of phytochemical compounds.

Results revealed that ethanol $25 \%$ is the most suitable solvent for the extraction of polyphenols and proanthocyanidins. A temperature of $60{ }^{\circ} \mathrm{C}$ for $15 \mathrm{~min}$ was optimal for the extraction of these compounds with minimal degradation. A yield of $13.91 \pm 0.72$ and $5.86 \pm 0.45 \mathrm{~g} / 100 \mathrm{~g}$ dry weight was obtained for polyphenols and proanthocyanidins, respectively. This yield was correlated with the best DPPH activity at $60.25 \%$.

Our results indicated that pistachio hulls could represent a valuable source of bioactive compounds that could be successfully employed in food, cosmetic and pharmaceutical industries.

\section{AUTHORS CONTRIBUTIONS}

All the author have contributed equally 


\section{CONFLICT OF INTERESTS}

Declared none

\section{REFERENCES}

1. Ozbek HN, Halahlih F, Goguş F, Yanık DK, Azaizeh H. Pistachio (Pistacia vera L.) hull as a potential source of phenolic compounds: evaluation of ethanol-water binary solvent extraction on antioxidant activity and phenolic content of pistachio hull extracts. Waste Biomass Valori; 2018. p. 1-10.

2. Paliwal R, Sharma V, Pracheta, Sharma S. Elucidation of free radical scavenging and antioxidant activity of aqueous and hydro-ethanolic extracts of Moringa oleifera pods. Res J Pharm Tech 2011;4:566-71.

3. Rosello Soto E, Galanakis CM, Brncic M, Orliend V, Trujilloe FJ, Mawsonf $\mathrm{R}$, et al. Clean recovery of antioxidant compounds from plant foods, byproducts and algae assisted by ultrasounds processing. Modeling approaches to optimize processing conditions. Trends Food Sci Technol 2015;42:134-49.

4. Zam W, Bashour G, Abdelwahed W, Khayata W. Simple and fast method for the extraction of polyphenol and the separation of proanthocyanidins from carob pods. Scholars Acad J Pharm 2013;2:375-80.

5. Jyothi B, Pratap GP, Husain MK, Kazmi MH, Prasad GP, Sudarsanam G. Scientific validation and standardization of parpataka an ayurvedic drug with respect to fumaria indica. Int J Curr Pharm Res 2019;11:134-41.

6. Ravindran NT, Mohamed Sadiq A. Pharmacological activity of Ulva lactuca polyphenols fraction: cardioprotective and antioxidant activities against isoproterenol-induced myocardial infarction in rats. Asian J Pharm Clin Res 2019;12:133-6.

7. Tumbas Saponjac V, Canadanovic Brunet J, Cetkovic G, Jakisic M, Djilas S, Vulic J, et al. Encapsulation of Beetroot pomace extract: RSM optimization, storage and gastrointestinal stability. Molecules 2016;21:584-99.

8. Hintz T, Matthews KK, Di R. The use of plant antimicrobial compounds for food preservation. BioMed Res Int 2015:1-12. http://dx.doi.org/10.1155/2015/246264

9. Saitta M, Giuffrida D, La Torre GL, Potortì AG, Dugo G. Characterisation of alkylphenols in pistachio (Pistacia vera $\mathrm{L}$.) kernels. Food Chem 2009;117:451-5.

10. Souri E, Amin G, Dehmobed Sharifabadi A, Nazifi A, Farsam H. Antioxidative activity of sixty plants from Iran. Iranian J Pharm Res 2004;3:55-9.

11. Hosseinzadeh H, Behravan E, Soleimani MM. Antinociceptive and anti-inflammatory effects of Pistacia vera leaf extract in mice. Iranian J Pharm Res 2011;10:821-5.

12. Rajaei A, Barzegar M, Mobarez AM, Sahari MA, Esfahani ZH. Antioxidant, anti-microbial and antimutagenicity activities of pistachio (Pistachia vera) green hull extract. Food Chem Toxicol 2010;48:107-12.

13. Taghizadeh SF, Davarynejad G, Asili J, Nemati SH, Karimi G. Assessment of phenolic profile and antioxidant power of five pistachio (Pistacia vera L.) cultivars collected from four geographical regions of Iran. Avicenna J Phytomed 2018;8:33-42.

14. Ozturk I, Ekici L, Yetim H, Sagdıc O. Antioxidative, antiradikale und antimikrobielle aktivitaten des fruchthullen-extrakts von frischen antep-pistazien. J Verbrauch Lebensm 2010;5:163-7.
15. Vahabzadeh F, Mehranian M, Mofarrah E. Antioxidant activity of pistachio hulls. J Am Oil Chem Soc 2004;81:621-2.

16. Zam W, Bashour G, Abdelwahed W, Khayata W. Effective extraction of polyphenols and proanthocyanidins from pomegranate's peel. Int J Pharm Pharm Sci 2012;4:675-82.

17. Tsao R. Chemistry and biochemistry of dietary polyphenols. Nutrients 2010;2:1231-46.

18. Waterhouse AL. Determination of total phenolics. In: Wrolstad RE, (Ed.), Current protocols in food analytical chemistry. Hoboken NJ: John Wiley and Sons. 2001. p. 1111-8.

19. Porter LJ, Histich LN, Chan BG. The conversion of procyanidins and prodelphinidins to cyanidin and delphinidin. Phytochemistry 1986;25:223-30.

20. Brand Williams W, Cuvelier ME, Berset C. Use of a free radical method to evaluate antioxidant activity. Lebensm Wiss Technol; 1995. p. 25-30.

21. Sajeeda N, Kolgi RR, Shivakumara SL, Shivaraj Y, Karigar CS. Comparative phytochemical profile and antioxidant property of bark, flowers and leaves extracts of Simarouba glauca. Asian J Pharm Clin Res 2019;12:56-63.

22. Zam W, Al Asaad N, Jarkas B, Nukari Z, Dounia S. Extracting and studying the antioxidant capacity of polyphenols in dry linden leaves (Tilia Cordata). J Pharmacogn Phytochem 2017;6:258-62.

23. Brglez Mojzer E, Knez Hrncic M, Skerget M, Knez Z, Bren U. Polyphenols: Extraction methods, antioxidative action, bioavailability and anticarcinogenic effects. Molecules 2016;21:E901.

24. Spigno G, Tramelli L, De Faveri DM. Effects of extraction time, temperature and solvent on concentration and antioxidant activity of grape marc phenolics. J Food Eng 2007;81:200-8.

25. Spirad G, Prakash V, Narasinga MS. Extractability of polyphenols of sunflower seed in various solvents. J Biosci 1982;4:145-52.

26. Bucic Kojic A, Planinic M, Tomas S, Jakobek L, Seruga M. Influence of solvent and temperature on extraction of phenolic compounds from grape seed, antioxidant activity and colour of extract. Int J Food Sci Technol 2009;44:2394-401

27. Sulaiman ISC, Basri M, Masoumi HRF, Chee WJ, Ashari $\mathrm{SE}$, Ismail M. Effects of temperature, time, and solvent ratio on the extraction of phenolic compounds and the anti-radical activity of Clinacanthus nutans Lindau leaves by response surface methodology. Chem Cent J 2017;11:54.

28. Shi J, Yu J, Pohorly J, Young JC, Bryan M, Wu Y, et al. Optimization of the extraction of polyphenols from grape seed meal by aqueous ethanol solution.J Food Agric Environ 2003;1:42-7.

29. Naczk M, Shahidi F. Extraction and analysis of phenolics in food. J Chromatogr A 2004;1054:95-111.

30. Vergara Salinas JR, Perez Jimenez J, Torres JL, Agosin E, Perez Correa JR. Effects of temperature and time on polyphenolic content and antioxidant activity in the pressurized hot water extraction of deodorized thyme (Thymus vulgaris). J Agric Food Chem 2012;60:10920-9.

31. Horzic D, Jambrak AR, Belscak Cvitanovic A, Komes D, Lelas V. Comparison of conventional and ultrasound-assisted extraction techniques of yellow tea and bioactive composition of obtained extracts. Food Bioprocess Tech 2012;5:2858-70. 